\title{
Infrared imaging technology and biological applications
}

\author{
GERALD KASTBERGER \\ University of Graz, Graz, Austria \\ and \\ REINHOLD STACHL \\ nbn Elektronik, Graz, Austria
}

\begin{abstract}
Temperature is the most frequently measured physical quantity, second only to time. Infrared (IR) technology has been utilized successfully in astronomy (for a summary, see Hermans-Killam, 2002b) and in industrial and research settings (Gruner, 2002; Madding, 1982, 1989; Wolfe \& Zissis, 1993) for decades. However, fairly recent innovations have reduced costs, increased reliability, and resulted in noncontact IR sensors offering mobile, smaller units of measurement (EOI, 2002; Flir, 2000, 2001, 2002). The advantages of using IR imaging are (1) rapidity in the millisecond range, facilitating measurement of moving targets, (2) noncontact procedures, allowing measurements of hazardous or physically inaccessible objects, (3) no interference and no energy lost from the target, (4) no risk of contamination, and (5) no mechanical effect on the surface of the object. All these factors have led to IR technology's becoming an area of interest for new kinds of applications and users. In both manufacturing and quality control, temperature plays an important role as an indicator of the condition of a product or a piece of machinery (EOI, 2002; Flir, 2000, 2001, 2002; Raytek, 2002). In medical and veterinary applications, IR thermometry is increasingly used in organ diagnostics, in the evaluation of sports injuries and the progression of therapy, in disease evaluation (e.g., breast cancer, arthritis, and SARS; Flir, 2003), and in injury and inflammation examinations in horses, livestock (Tivey \& Banhazi, 2002), and zoo animals (Hermans-Killam, 2002a; Thiesbrummel, 2002). Lastly, physiological expressions of life processes in animals (Kastberger, Winder, \& Steindl, 2001; Stabentheiner, Kovac, \& Hagmüller, 1995; Stabentheiner, Kovac, \& Schmaranzer, 2002; Stabentheiner \& Schmaranzer, 1987) and plants (Bermadinger-Stabentheiner \& Stabentheiner, 1995) can be monitored. The most recent field in which IR technology has been applied is animal behavior. This article focuses on the practical options for noncontact IR thermometryin particular, in biological applications.
\end{abstract}

\section{TECHNICAL OVERVIEW OF IR MEASURING SYSTEMS}

\section{Measurement Principles}

All objects emit characteristic IR radiation as a function of their temperature, because of the internal mechanical movement of molecules. Since the molecular movement represents charge displacement, electromagnetic radiation in the form of photon particles is emitted. These photons move at the speed of light and behave according to known optical principles. They can be deflected, focused with a lens, or reflected from surfaces.

We thank Helmut Käfer (Graz) for assistance with infrared recording from giant honeybees in Assam, epo-film (Vienna-Graz) for logistic help, and nbn Elektronik Graz for providing the infrared camera (Inframetrics PM280/3.5-5.0 $\mu \mathrm{m}$ ) in Assam, supported by a grant from the Austrian Science Fund (FWF), Project P 13210-BIO. We also thank FLIR Infrared Camera Systems, Boston, and Raytek Systems AG, Chur, Switzerland. Correspondence concerning this article should be addressed to G. Kastberger, Institute of Zoology, University of Graz, A 8010 Graz, Austria (e-mail: gerald.kastberger@uni-graz.at).
The wavelength of this radiation ranges from 0.7 to $1,000 \mu \mathrm{m}$ (for summaries, see DeWitt, 1988; Orlove, 2002; Stahl, 1980; Wolfe \& Zissis, 1993).

The electromagnetic spectrum from 0.7 to $14 \mu \mathrm{m}$ is useful for IR measuring purposes - in particular, the mid-wave (3-5 $\mu \mathrm{m})$ and long-wave $(8-14 \mu \mathrm{m})$ bands. The Planck curves (Figure 1) show the typical radiation of a body at different temperatures. The radiation maximum moves toward shorter wavelengths as the target temperature rises (according to the Wien displacement law), and the curves do not cross at different temperatures. For moderate temperatures, the invisible part of the spectrum contains up to 105 times more energy than does the visible part. The radiant energy in the entire wavelength range is displayed by the area beneath each curve; it increases, to the power of four, with the temperature according to the StefanBoltzmann law and illustrates that an unambiguous temperature can be measured from the radiation signal.

\section{Major Limitations}

The goal should be to set up the IR thermometer for the widest range possible, in order to gain the most en- 


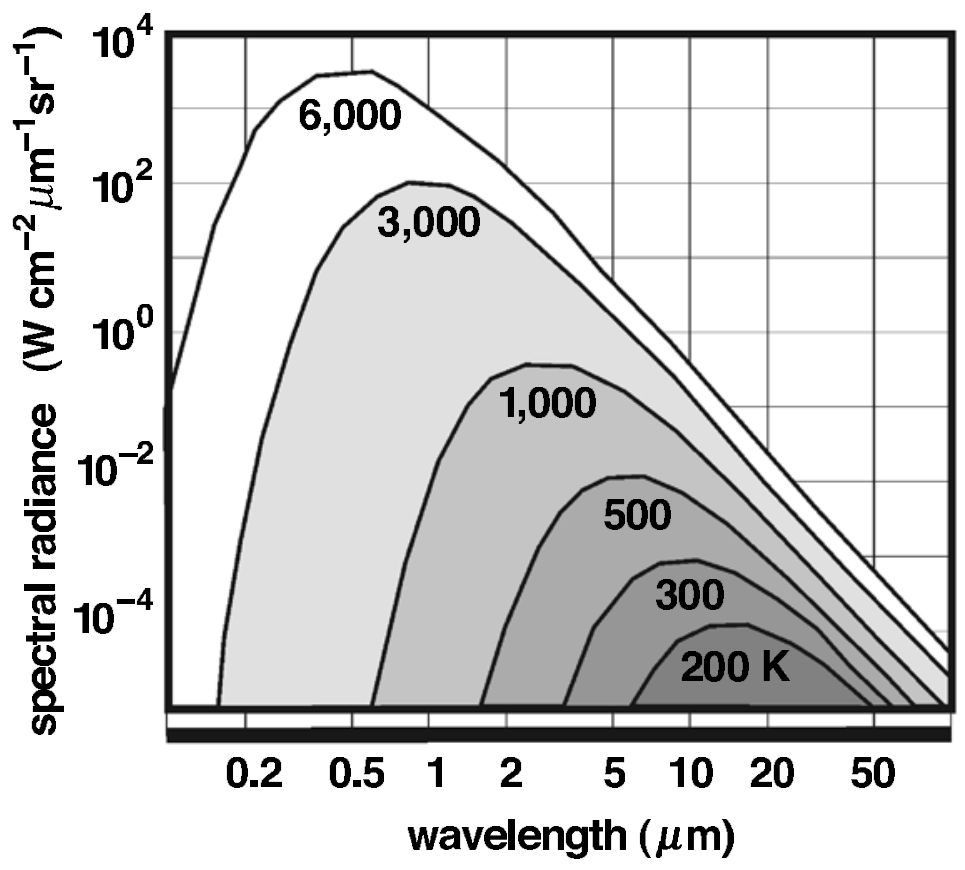

Figure 1. Planck curves of a black body (after Flir, 2000) at different temperatures (in degrees Kelvin). Ordinate, spectral radiance [W cm$\left.{ }^{-2} \mu \mathrm{m}^{-1} \mathbf{s r}^{-1}\right]$; abscissa, wavelength in micrometers.

ergy or signal from the target. However, there are two consequences resulting from the Planck curves (Figure 1). First, for low-temperature applications (from -50 to $+200^{\circ} \mathrm{C}$ ), long-wave systems are the method of choice, because mid-wave systems would not effectively detect low-temperature radiation. Second, the energy curves (Figure 1) display much higher values at shorter wavelengths than at longer wavelengths. Thus, an IR thermometer should be used at its shortest possible wavelength within its temperature range, in order to maximize the quantity of radiance and the accuracy of the IR detector per temperature step.

\section{Emissivity}

A black body is defined as a hypothetical object that does not reflect but only emits radiation. Real plants and

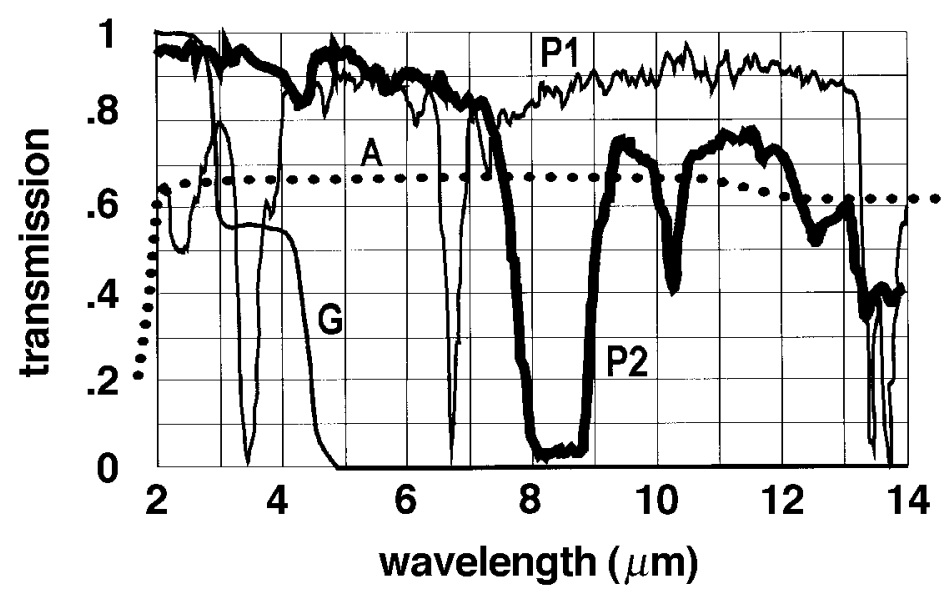

Figure 2. Infrared transmissivity (ordinate) of different materials (after Gruner, 2002). A (spotted line), AMTIR; G, glass; P1 (thin line), polyethylene; $\mathbf{P 2}$ (thick line), polyester; abscissa, wavelength in micrometers. 


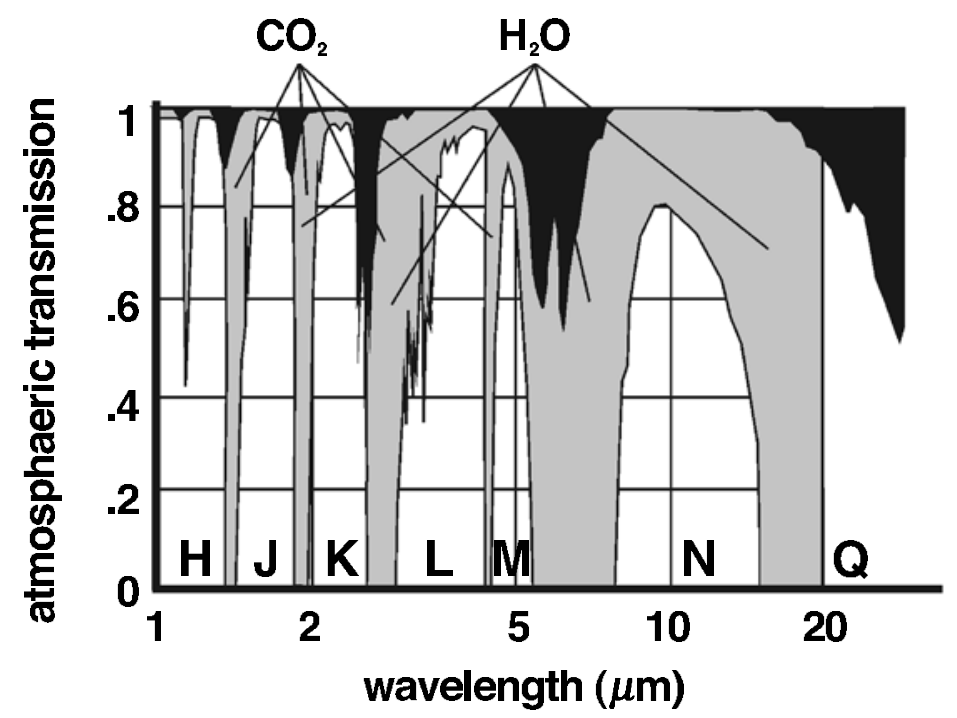

Figure 3. Infrared transmissivity in air (after Hermans-Killam, 2002b). There are eight windows (bands) in the atmosphere. Short-wavelength bands, $H$ and $J$; mid-wavelength bands, $K, L$, and $M$; long-wavelength bands, $N$ $(8-14 \mu \mathrm{m}), Q(28-40 \mu \mathrm{m})$, and $Z$ (330-370 $\mu \mathrm{m}$; not shown here). The sky transparency is fairly high for the $\mathrm{H}$ to $\mathrm{L}$ bands but is rather low at longer wavelengths. The gray areas signify absorption in the atmosphere-in particular, because of carbon dioxide and water vapor. The black areas give the transmissive condition in air at a distance of $1 \mathrm{~m}$ at $32^{\circ} \mathrm{C}$ and $75 \%$ humidity.

animals are considered to be gray bodies because they reflect IR radiation. IR cameras assume gray body validity, since they normally measure over a range of wavelengths (e.g., 3.4-5.0 or 8-14 $\mu \mathrm{m}$ ). However, the gray body approximation causes problems when the target emissivity varies with wavelength. The most direct solution to this problem is to measure the emissivity of a nongray target at the temperature that is the same as that which occurs in use (Madding, 2002). As the technology of thermography evolves, many applications have increasingly stringent requirements for quality temperature measurement. Today's IR cameras and software can correct for target emissivity variations on a point-bypoint basis or over the entire image.

Many nonmetallic materials, such as wood, plastic, rubber, rock, or concrete, have surfaces that reflect very little and have high emissivities $(\varepsilon=0.80-0.95)$. Also, organic materials, such as the thoracic cuticular surface of foraging honeybees, have emissivities between 0.955 and 0.990 (Stabentheiner \& Schmaranzer, 1987), which is as close to the emissivity of a black body as that of the skin of humans or other mammals (Steketee, 1973; Watmough \& Oliver, 1968). By contrast, measuring the temperature of metals is complex, because their emissivities change with temperature and wavelength (Gruner, 2002; Wolfe \& Zissis, 1993).

\section{Environmental Conditions}

Measuring Objects Through Protecting Layers

Some applications require separation of the targets from the measuring device by protecting layers. For that, it is necessary to know the wavelength band of highest transmittance of the protective material (Figure 2). The transmittance of amorphous material transmitting IR radiation (AMTIR; Janos, 2002), a glass-like amorphous

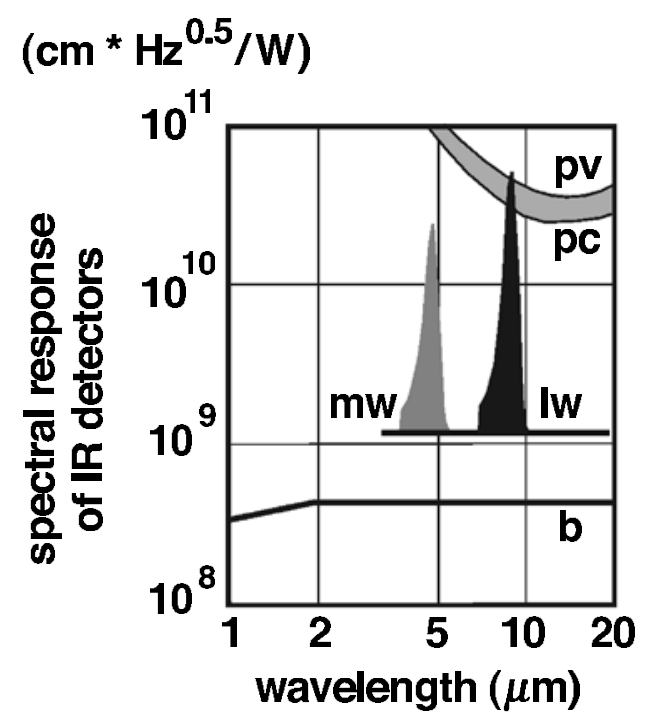

Figure 4. Spectral responses of infrared (IR) detectors (from Flir, 2000). Mid-wave ( $\mathrm{mw}$ ) and long-wave (lw) quantum well infrared photon detectors are cooled detector systems for fast responses. The bolometer (b) represents an uncooled IR detector system for responses $<90 \mathrm{~Hz}$. For comparison, ideal photoconductive (pc) and photovoltaic (pv) IR spectral responses are shown. Abscissa, wavelength in micrometers; ordinate, spectral response of IR detectors in $\left(\mathrm{cm} * \mathrm{~Hz}^{0.5} / \mathrm{W}\right)$. 

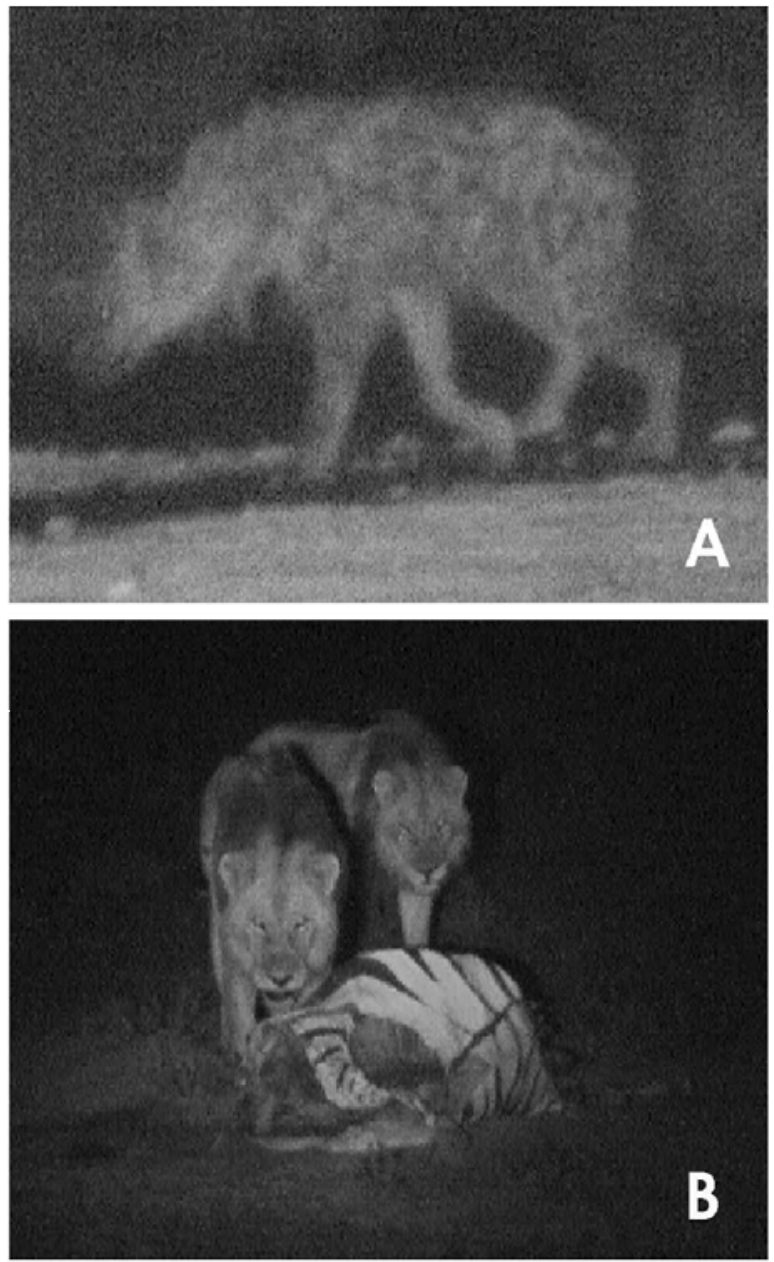

Figure 5. (A) A female hyena and (B) two lions at a zebra kill in Etosha, Namibia (after Trinkel \& Kastberger, 2003). A nightshot option of a video camera without $(A)$ and with $(B)$ near-IR spotlight illumination is shown. The distance between the camera and the target was less than $15 \mathrm{~m}$.

material with a high homogeneity, is often used for IR lenses. Plastic material generally varies with the wavelength and is proportional to its thickness: Polyethylene, polypropylene, nylon, and polystyrol are not transmissive at $3.43 \mu \mathrm{m}$; polyester, polyurethane, Teflon FEP, and polyamide are not transmissive at $7.9 \mu \mathrm{m}$; quartz glass is transmissive only up to $2.2 \mu \mathrm{m}$ (Gruner, 2002).

\section{Air Humidity}

Another reason for setting up an IR thermometer only for a particular spectral range is the absorption behavior of the transmission path, usually the ambient air. Certain components of the atmosphere, such as vapor and carbon dioxide, absorb IR radiation at particular wavelengths (Hermans-Killam, 2002b; see Figure 3). If absorption media are not taken into account, data assessment can lead to a temperature's being displayed as lower than that of the actual target. Typical measuring windows used for IR are
$1.1,1.7,2.25,3.5$, and $8-14 \mu \mathrm{m}$. Since the manufacturers have already furnished IR measuring devices with atmospheric correction filters, the user is spared such worries.

\section{Ambient Temperature}

In addition to humidity, thermal radiation in the environment surrounding the target should likewise be taken into account. It can be generally compensated for with external measurements; however, many manufacturers have taken this into consideration and offer IR cameras with a built-in thermal radiation compensation (Gruner, 2002).

\section{Detectors}

The core of the IR thermometer is the detector system. It converts the IR radiation received into electrical signals,
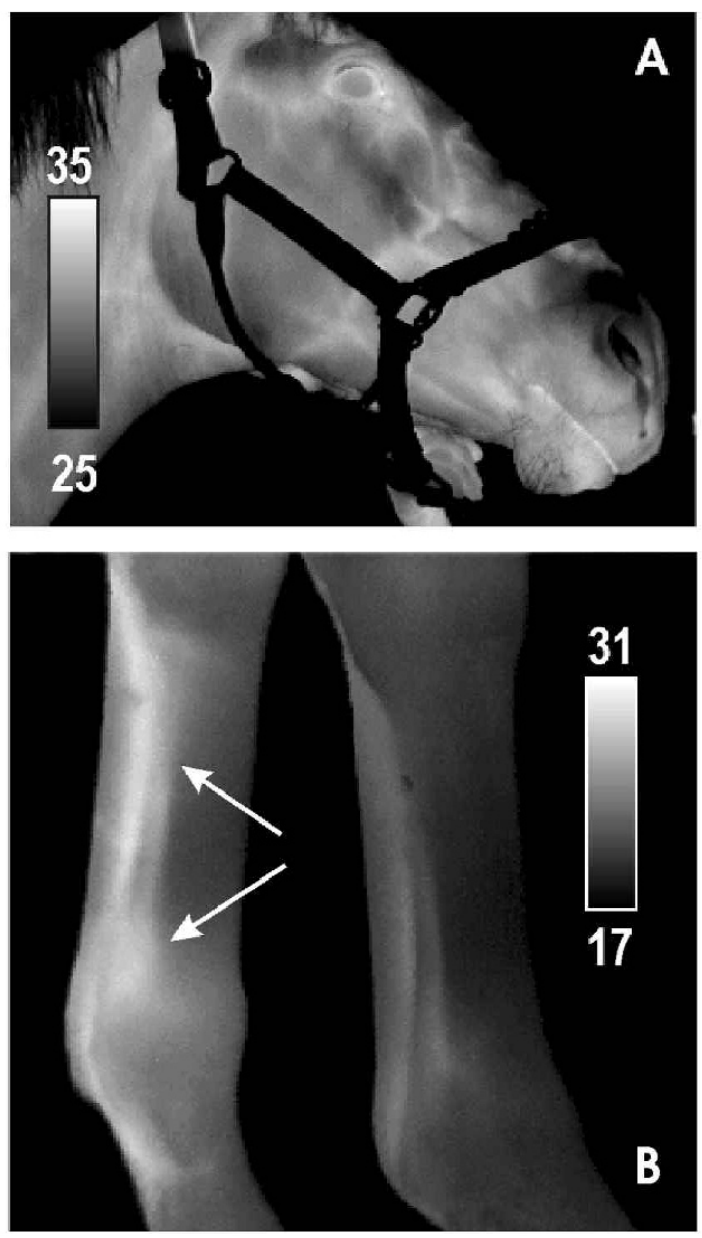

Figure 6. Infrared (IR) thermograms of a horse's head (panel A) and hind legs (panel B), after Fuchs (2002). Scaling is in degrees Celsius. A focal plane IR mid-wave PtSi quantum detector camera was used. (A) Normal thermogenic pattern of the horse head. (B) IR thermography makes visible pathogenic temperature patterns on the surface of the skin; here, the left hind leg patellar tendon is heavily inflamed. Asymmetry in thermogenic patterning is one of the important criteria for spotting pathogenically increased or decreased circulation under the skin. 
which are then emitted as temperature values by the electronic system. In addition to reducing the cost of IR thermometers, the most recent developments in processor technology have meant increases in system stability, reliability, resolution, and speed. Today's detectors range in format from single-element, uncooled detectors to specialized, multispectral, staring array detectors (EOI, 2002; Hermans-Killam, 2002b). There are two main classes of infrared detectors, with several types within each class: thermal detectors and quantum detectors. Selection of a specific detector depends on the wave band of interest, the sensitivity, the speed required, and cost constraints.

Thermal detectors change their temperature depending on the impacting radiation. They are heated up by radiation and create a voltage by the temperature change. Due to the self-heating required, they are slower (in the range of milliseconds) than quantum detectors (in the range of nanoseconds). Thermopiles are the oldest type
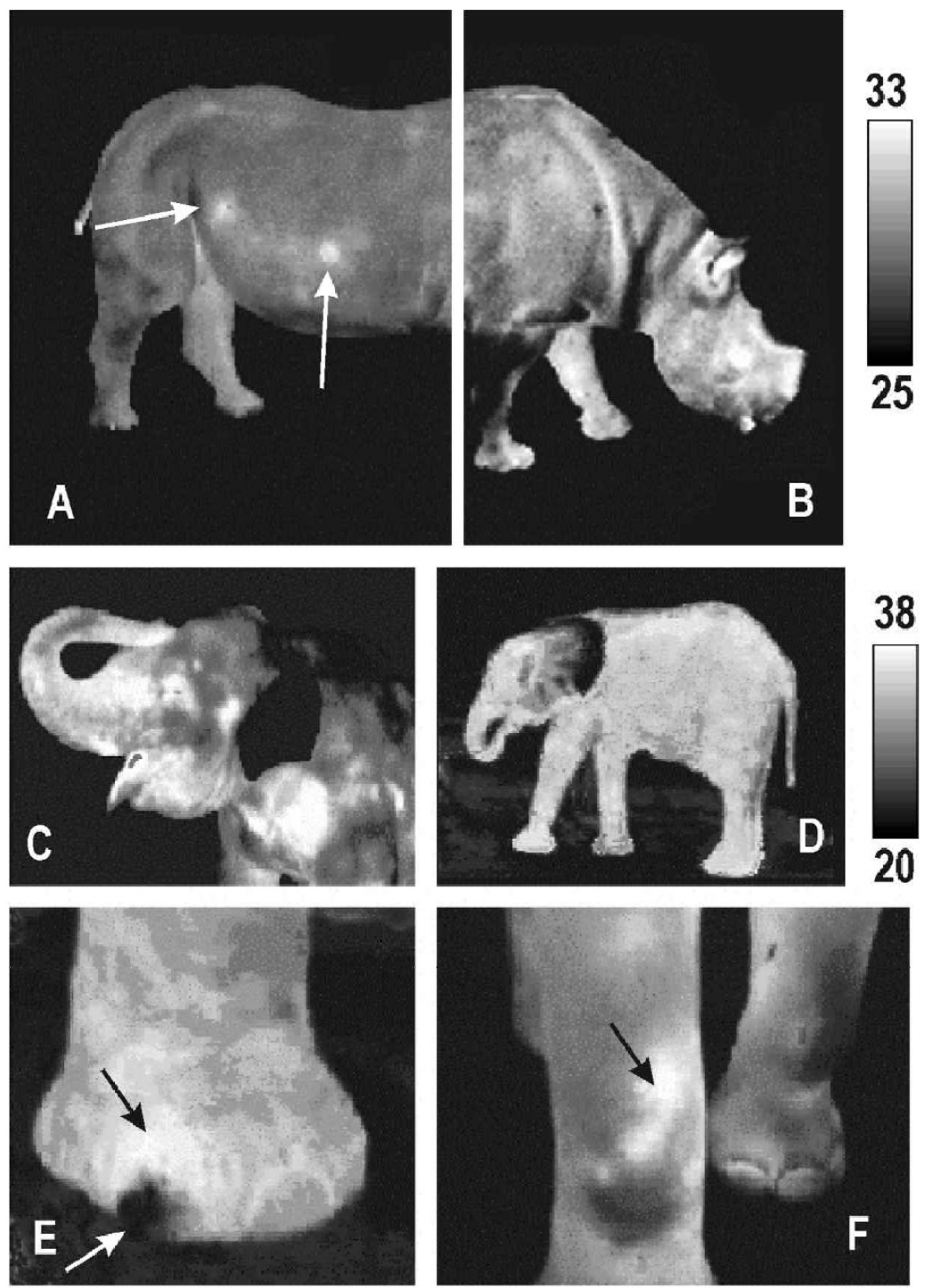

Figure 7. Infrared (IR) thermograms of a rhinoceros (A and B) and of elephants (C-F), after Thiesbrummel (2002). Scaling is in degrees Celsius. A long-wave microbolometer camera was used. (A) IR thermogram allowing pregnancy diagnosis; the embryo presses against the side tissues and brings heat to the skin. The next panels show the normal thermogenic pattern of a young elephant's (C) head and (D) body. (E) Right foreleg of an older elephant with dead phalangar tissue and heavy inflammation above this cold spot. (F) Inflammation site above the joint of the right foreleg. 

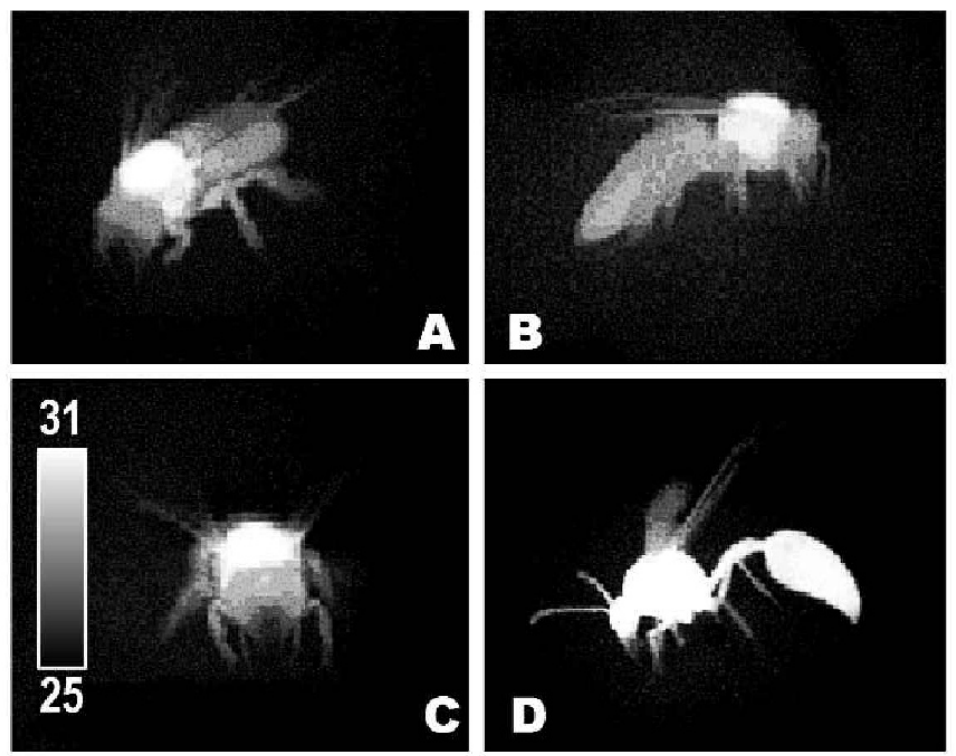

Figure 8. Infrared (IR) thermograms of (A, B, and C) water-drinking honeybees and (D) a digger wasp. Scaling is in degrees Celsius. A focal plane IR mid-wave PtSi quantum detector camera was used. The thoracic muscles of the bee were heated up to $30^{\circ} \mathrm{C}$; the body of the wasp was generally $33^{\circ} \mathrm{C}$, which indicates that it had spent the time before in direct sunlight. The resolution of modern focal plane IR cameras is good enough to trace fine appendages, such as insect legs and antennae.

of infrared detectors (EOI, 2002; Raytek, 2002) and utilize thermo-electromotive force generated between two different types of conductors. Pneumatic detectors work either by Golay cells, in which sealed xenon gas expands when it is warmed by incident IR radiation, or by capacitor microphones, whereby the varying expansion of the gas affects the capacitorfilm, which in turn produces the variation in the electrostatic capacity. An electric charge is then generated on the surface of the crystal in accordance with the amount of temperature variation. In piezoelectric detectors, temperature changes generate an electric charge on the surface of the crystal.

The most recent technology for imaging systems, which has become the focus of most uncooled detector development, involves the microbolometer (Flir, 2000), which detects change in resistance in a matrix of sensor pixels with high linearity (Figure 4) and gain stability. However, since radiation from internal parts of the measuring device is 10 times higher than object radiation, an accurate system for keeping track of internal radiation is needed. This is achieved by an advanced automatic temperature compensation system based on accurate temperature sensors and a temperature reference using neural network algorithms.

Quantum detectors (photon detectors) convert radiation directly to an electrical signal as they interact directly with the impacting photons, resulting in electron pairs and, therefore, an electrical signal. Quantum detectors are often used for imaging systems and line scanners (Flir, 2000). They are very sensitive and stable, but for low-temperature applications and imaging systems, they need cooling. The mid-wave detector commonly refers to PtSi and InSb technologies; the long-wave detector is designed by the most recent quantum well IR photon (QWIP) GaAs technology. The QWIP detectors have high thermal sensitivity (Figure 4), high uniformity, and a very low fixed pattern noise, and they will represent an easier step when larger detector arrays are produced in the future.

\section{Alternative Methods to IR Thermography \\ IR Photography}

Specially sensitized photographic emulsions can record a radiation of $0.7-0.9 \mu \mathrm{m}$ (for a summary, see Kodak, 2002). The targets in this range, such as stoves, engine parts, or high-pressure boilers, are just below red heat levels, at a temperature of $250^{\circ}-500^{\circ} \mathrm{C}$. By contrast, electronic thermography can be used on objects with temperatures ranging from $-40^{\circ} \mathrm{C}$ to more than $1,500^{\circ} \mathrm{C}$.

Near-IR radiation has the ability to penetrate aerial haze, which makes it valuable in aerial photography. IR color photography is a technique that provides even greater differentiation than black-and-white IR photography does. An important application is the monitoring of foliage, producing a unique tonal differentiation. Since the 

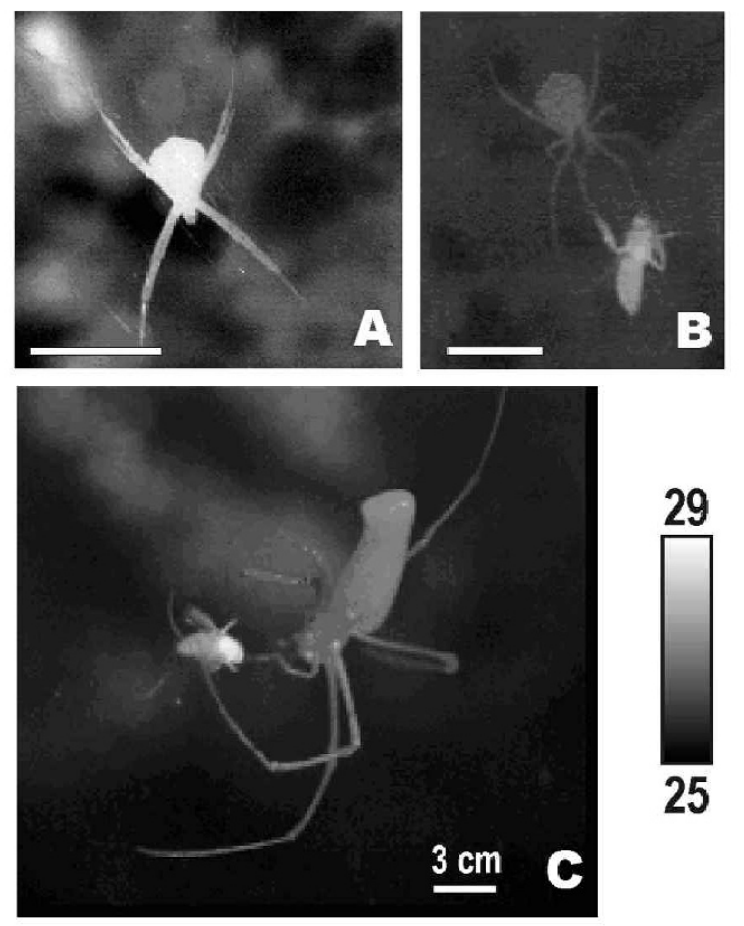

Figure 9. Infrared (IR) thermograms of interactions between the tiger spider Argiope (panels A and B) and the Nephila spider (panel C) with giant honeybees Apis dorsata in Assam. Scaling is in degrees Celsius. A focal plane IR mid-wave PtSi quantum detector camera was used. The web of the Argiope was positioned just in front of the nest of the giant honeybee. Regularly, nestwarm bees touched the web on their orientational flights and got trapped. The spider was near ambient temperature; the bees were generally warmer. (A) The trapped bee displayed on the top left, unfocused in the background. (B) The thorax of the woven honeybee was less than $30^{\circ} \mathrm{C}$; it was still alive, although it had been poisoned by the spider. (C) The Nephila spider starts to web a freshly trapped bee, to conserve it for later use; the bee itself still remained in take-off state and exhibited a hot thorax.

internal structure of leaves reflects IR strongly, they appear lighter in tone in the IR photograph. Besides that, conifers appear darker than deciduous trees; diseased fruit and vegetable crops or those suffering climatic or nutritional stress can be detected before trouble becomes apparent visually (Kodak, 2002).

\section{Night Vision Goggles}

Amplifying small amounts of visible or near-IR lightfor example, under moon- or starlight conditions - makes objects visible at night. This is used for night observation of mammals (Figure 5). Most video cameras are sensitive in near-IR light, and their intrinsic photo-multiplier technology (night-shot option) is commonly used in combination with a high-energy near-IR flashlight to enlarge the outcome of the imaging. However, one major disadvantage of the night vision goggle device (Night Vision
Goggles, 2002) is that it can be easily blinded by shining a flashlight at it. In contrast, thermal imagers look only at the heat and are totally unaffected by light sources.

\section{BIOLOGICAL APPLICATIONS OF IR IMAGING}

\section{Veterinary Field}

\section{Stock Production}

IR thermography has proved to be increasingly useful as a research tool by which to investigate the physiology of energy utilization by farm animals-for example, in pig production (Dauncey \& Ingram, 1983; Tivey \& Banhazi, 2002). Thermal imaging of pigs and of the housing within which they are kept will allow objective assessment of the environment and the thermal comfort of animals under a given management regime and, thereby, provide information for decision making to maximize pig growth and profitability of the unit. Such specific goals can be assessment of temperature variation over the structural components of production sheds, the impact of spray cooling and skin wetness on skin surface temperature, and the monitoring of heat production from animals and, hence, their metabolic activity at rest, when active, or during and after feeding.

\section{Horses}

The first use of IR thermography for clinical applications on horses occurred roughly in 1963. Because of the small portable-sized, uncooled, low-cost microbolometric IR cameras, their use in equine injury diagnosis is quite practicable (for a summary, see SPI, 2002). In particular, locomotor injuries in bones, joints, tendons, and muscles are easily located (Fuchs, 2002). IR thermography visualizes characteristic, unusual, or pathogenic temperature patterns on the surface of the skin. Areas of increased heat designate increased blood flow, which can be correlated with inflammation, injury, or abscesses; cold spots show decreased circulation due to nerve damage, blood clot, or scar tissue (Figure 6). The IR diagnostic system, used in combination with a clinical exam and other imaging modalities, provides highly effective results by pinpointing areas of suspicion.

\section{Zoo Animals}

The first reports on the use of IR thermography in the observation of zoo animals (for a summary, see Boldstar, 2002; Hermans-Killam, 2002a) involved diagnoses of pregnancies (Figures 7A and 7B), inflammations, and dead tissues (Figures 7E and 7F) without narcosis. Figure $7 \mathrm{E}$ shows a dead phalange from an elephant, with inflammation zones above it. The view of the Asian elephant head (Figure 7C) shows a normal thermal pattern. Thicker layers more exposed to ambient temperature, such as the cheeks, are cooler, and the trunk ending is warmer because of respiration. The areas around the eyes and the lips are warmer due to thinner skin. The ears (Fig- 

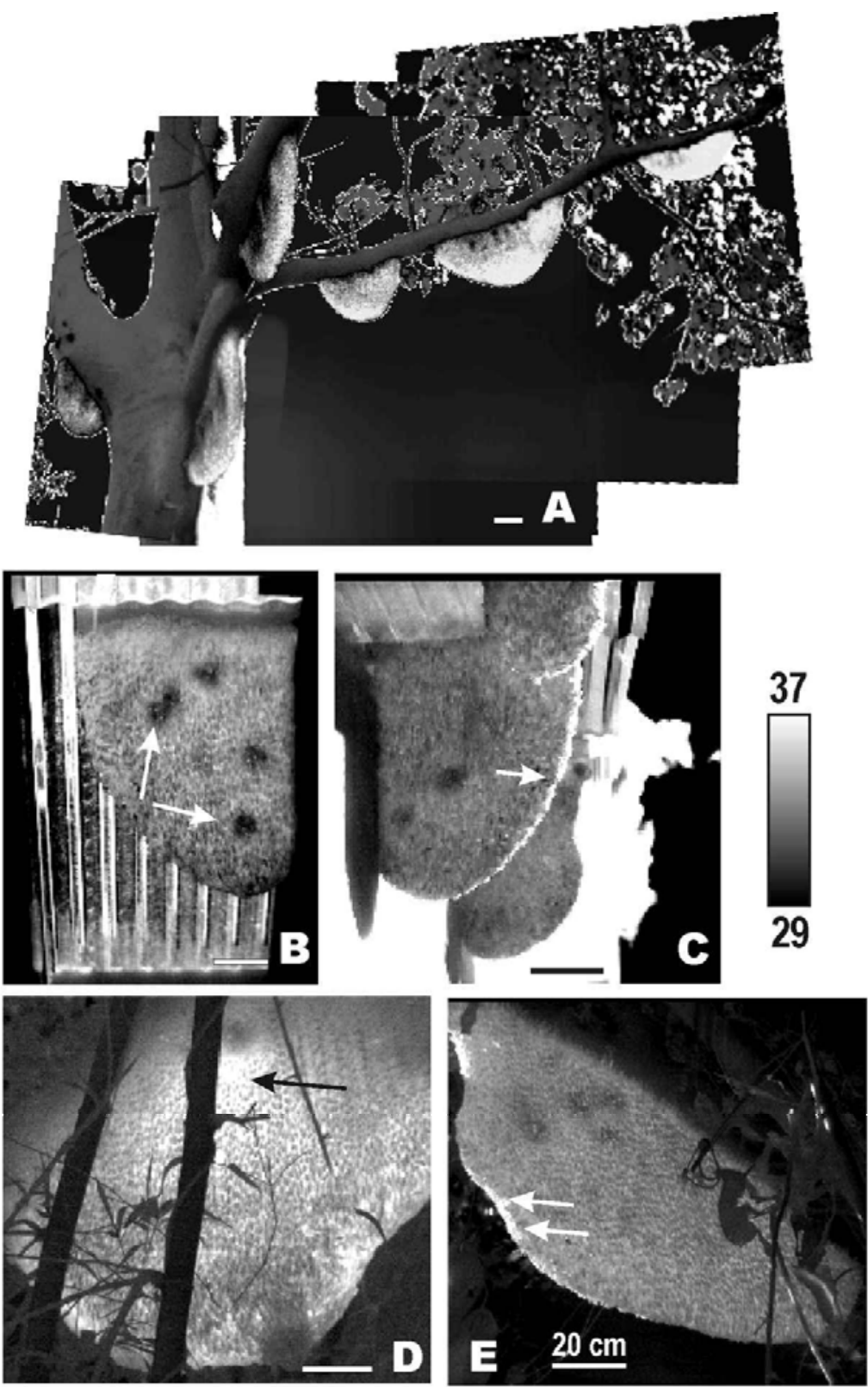

Figure 10. Infrared (IR) thermograms of nests of the giant honeybee Apis dorsata. Gray scaling is in degrees Celsius. A focal plane IR mid-wave PtSi quantum detector camera was used. Horizontal bars give the length of $20 \mathrm{~cm}$. (A) Six nests on a traditional bee tree; at this time, a total of 100 colonies were aggregated on this tree (Assam, India). The warmer regions represent mouth zones. (B and C) Nests on a corrugated iron roof of a farmer's house in Assam; note the sunny nest rims (white arrow in panel $C$ ) and the black shadow on the house wall at the left. The house walls were far above $40^{\circ} \mathrm{C}$. The roofs were cooler; otherwise, the combs would have melted. (D and $E$ ) Nests in bamboo bushes. The colonies display cold spots in the nest surfaces $(B, C$, and $E)$, which were convection holes in which bees fan the air (cooled by evaporating water) toward the brood inside the nest. In panel $D$, the hot area (black arrow) signifies the actual brood area of the nest; the hot areas below (white arrows) are mouth zones. Since this is an early morning observation, the bees have just started to forage; therefore, the mouth zones are small in comparison with the situation at midday on the tree $(\mathrm{A})$. 

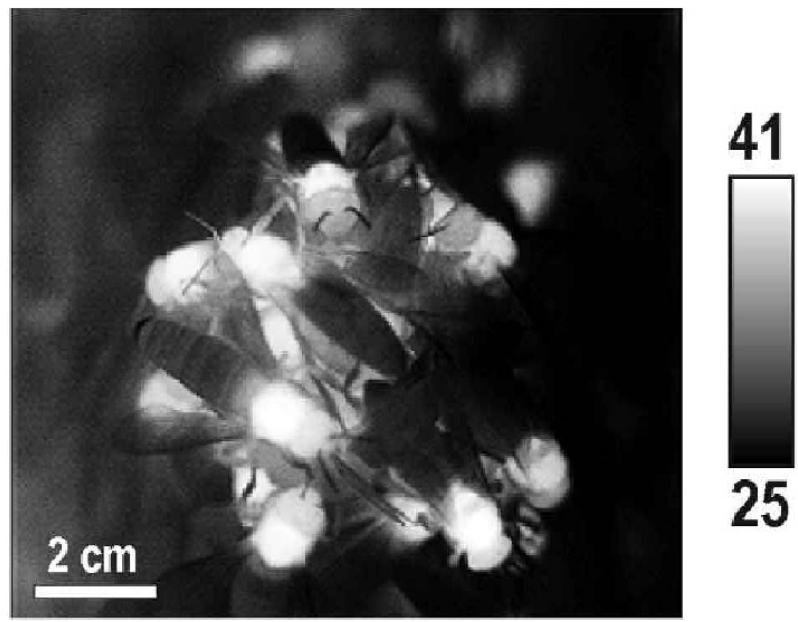

Figure 11. Infrared (IR) thermograms of the giant honeybee Apis dorsata killing a wasp by heating it up. Gray scaling is in degrees Celsius. A focal plane IR mid-wave PtSi quantum detector camera was used. The heat balling of a wasp is shown. Guard bees selectively heat up their thoracic muscles and cling around the intruder. The heat inside the ball increases by up to $48^{\circ} \mathrm{C}$, which is lethal for the wasp, but not for the honeybees.

ures 7C and 7D) represent the coldest zones of the body; they have a relatively thin skin but are highly vascularized and are, therefore, used for cooling.

\section{IR Ethometry in Giant Honeybees}

The examples of the behaviors illustrated in the Figures 8-12 refer to observations in subtropical and tropical habitats. Therefore, the IR equipment had to meet the demands of field application, which are robustness, portable hand-held size, rapidity, and accuracy.

\section{The Heating Up of Thoracic Muscles}

Honeybees are bound to characteristic thermogenic activity. They are able to selectively heat up the thoracic muscles for a variety of purposes: to prepare themselves for flight, to dance (Stabentheiner et al., 1995), to contribute to the colony homeothermy in the nest (Stabentheiner \& Schmaranzer, 1987), to prepare for defense purposes (Kastberger et al., 2001), or for nest mate recognition (Stabentheiner et al., 2002). Without IR, thermoactive bees cannot be distinguished in their behaviors from bees of ambient temperature. In Figure 8, giant honeybees and a digger wasp are displayed while drinking water and just before take-off. At this moment, the thoracic muscles have been activated and heated up several degrees. A similar thermographic pattern was present when a giant honeybee collided with a spiderweb and was trapped (Figures 9B and 9C).

\section{Intrinsic Features of Nest Architecture}

The nest of the Asian giant honeybee Apis dorsata consists of a single comb covered by several layers of bees forming a "curtain" (Butler, 1962; Morse \& Laigo,
1969; Roepke, 1930). The IR images of the nests clearly appear in contrast with house walls and roofs (Figures $10 \mathrm{~B}$ and 10C) or with ambient foliage (Figures 10A, 10D, and 10E). Under higher ambient temperatures, colder spots can be discerned that belong to an intrinsic vascular system, facilitating the cooling of the inner layers of the nest at the comb, which provides the homeothermic condition for the brood. Besides that, there is also an overall thermal pattern of the nest, which may vary throughout daytime. In the "mouth" zone (Morse \& Laigo, 1969) the forager bees depart and arrive, feed the nest mates, and perform their dances (Figures 10A and $10 \mathrm{D})$; in the other, more quiescent zones, the bees display near-ambient temperature; they hang vertically with the head up, practically without motion. In particular, in those nests that have only one or two layers of bees, the warmer brood zones produce characteristic thermic emissions (Figure 10D).

\section{Defense Behaviors}

The Asian giant honeybee Apis dorsata nests in the open and, therefore, is exposed to its major natural predators: wasps and such birds as drongos, swallows, honey buzzards, and bee eaters (for a summary, see Kastberger \& Sharma, 2000). In response to this pressure, the bees have evolved an imposing set of antipredator strategies (Kastberger \& Biswas, 1998; Kastberger, Winder, Biswas, \& Raspotnig, 1998; Kastberger et al., 2001; Kloft \& Schneider, 1969; Koeniger \& Fuchs, 1975; Morse \& Laigo, 1969; Seeley, Seeley, \& Akratanakul, 1982).

Killing by heating. Bees cannot kill wasps by stinging, because the stingers cannot penetrate the cuticular armor of the wasp; the honeybees kill by heating up the wasps. This behavior is called thermal killing; it occurs in all Apis species and was first described for Apis cerana (Ono, Igarashi, Ohno, \& Sasaki, 1995). To study this behavior in Apis dorsata, a wasp tethered by a thin thread was artificially brought to a nest. When a wasp touches a nest, surface bees immediately grasp and ball around it (Figure 11). All of a sudden, the balling bees heat up, with a resulting heat inside the ball of $45^{\circ}-48^{\circ} \mathrm{C}$, which kills the wasp within 10 min.

Recruitment of soldier bees and mass release. Bigger predators, such as birds or mammals, may be repelled by the most impressive defense strategy of giant honeybees, the mass release of defense guards (Kastberger \& Sharma, 2000; Koeniger \& Fuchs, 1975; Lindauer, 1956; Morse \& Laigo, 1969). Thousands of bees may be deployed within seconds to pursue an invader for a distance of a kilometer or more. For that, a complex phase of recruitment must first occur to make the colony "sharp," ready to counterattack. It takes from $15 \mathrm{sec}$ to several minutes to bring a colony into such an arousal state that the bees start to attack. We disturbed a nest in Assam (India) by throwing small stones onto it and imaged the temperature patterning of the nest surface. In undisturbed nests, only a small number of bees with warm 

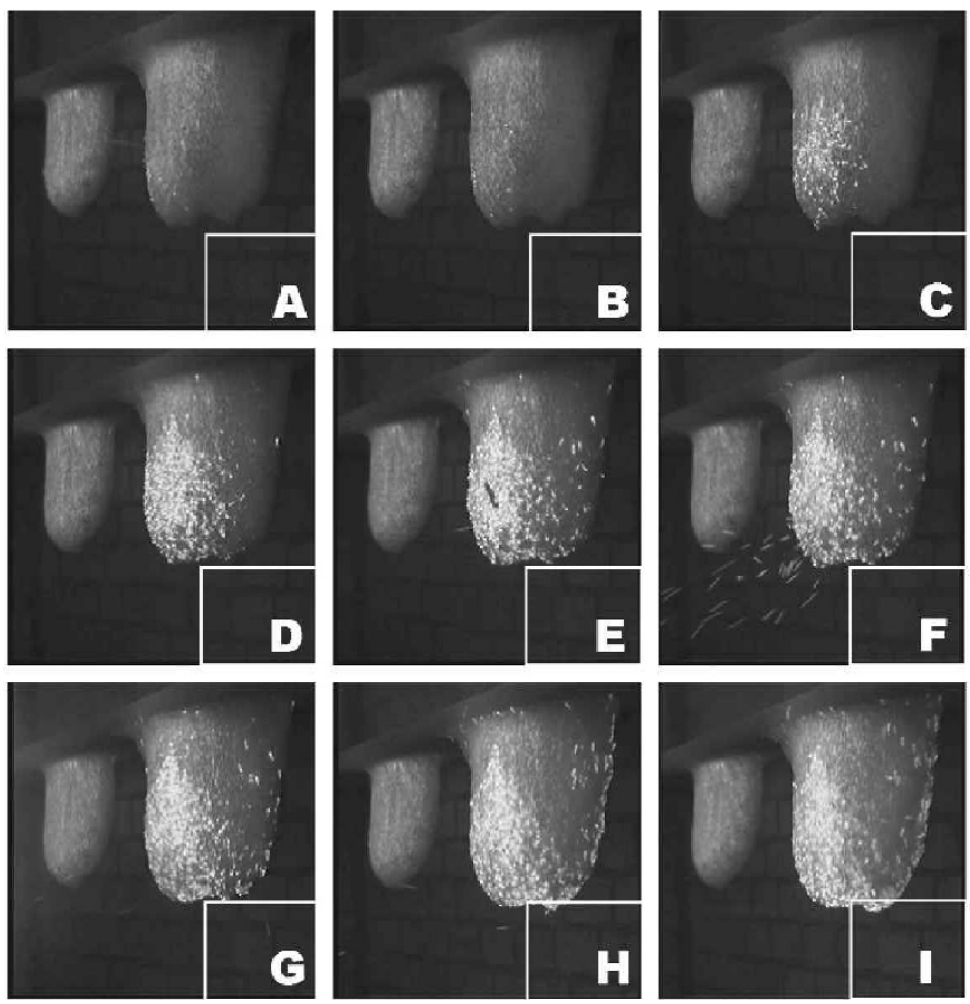

Figure 12. Infrared (IR) documentation of the recruitm ent of soldier bees in a nest of the giant honeybee Apis dorsata. Gray scaling is in degrees Celsius. A focal plane IR mid-wave PtSi quantum detector camera was used. The experiment lasted $10 \mathrm{~min}$. The colony status within the first $150 \mathrm{sec}$ is displayed, at 1.8, 9.2, 21.2, 41.2, 61.7, 62.4, 74.2, 112.0, and 152.0 sec in panels A-I, respectively. (A) A small stone was thrown at the nest. (B) Within 20 sec, the first nest-warm bees come out from the inner layers to the surface. ( $C$ and $D$ ) More and more nest-warm bees, alarmed by the disturbance, came to the surface. (E) Another small artifact was thrown at the center of the nest. (F) Within a fraction of a second, some of the recruited defense group were released to attack the intruder. (G-I) Subsequently, the recruited defense guard stays at the surface and cools down; simultaneously, the bee curtain grows significantly downward (note the position of the lower nest rim relative to the white rectangle).

thoraces can be observed. Such bees are not going to fly off, as foragers would; therefore, they are assumed to be guard bees (Figure 12A). They patrol on the surface of the nest and are ready to attack an intruder by taking flight. After a disturbance, within $30 \mathrm{sec}$, nest-warm bees from deeper layers are mobilized to emerge on the surface of the nest. They are characterized by a uniform temperature of $37^{\circ} \mathrm{C}$ over the entire body (Figures 12B12D). A subsequent disturbance lets these bees depart from the nest like a spray in order to attack and repel the intruder (Figure 12F). After that, the nest cools down, but the bee curtain still grows (Figures 12G-12I), signifying that the colony is still ready to attack.

\section{REFERENCES}

Bermadinger-Stabentheiner,E., \& Stabentheiner, A. (1995). Dynamics of thermogenesis and structure of epidermal tissues in inflorescences of Arum maculatum. New Phytologists, 131, 41-50.

BOLDSTAR (2002). Boldstar infrared services helps zoo staff with ailing elephant. Retrieved November 20, 2002 from http://www.bold starinfrared.com/elephants.html.

ButLer, C. G. (1962). The world of the honeybee. London: Collins. DAunceY, M. J., \& INGRAM, D. L. (1983). Evaluation of the effects of environmental temperature and nutrition on growth and development. Journal of Agricultural Sciences, 101, 351-358.

DeWITT, N. (1988). Theory and practice of radiation thermometry. New York: Wiley.

EOI (2002). [Electro Optical Industries, Inc. homepage]. Retrieved November 20, 2002 from http://www.electro-optical.com.

FLIR (2000). Detector technology: Infrared everywhere 2000. Retrieved November 20, 2002 from http://www.flirthermography.com/english/ Default.asp.

FLIR (2001). Parameters to consider when buying a research camera. Retrieved November 20, 2002 from http://www.flirthermography. com/english/Default.asp.

FLIR (2002). FLIR Systems launches two revolutionarynew product lines; new low cost infrared cameras will open new markets. Retrieved November 20, 2002 from http://www.corporate-ir.net/ireye/ir_site. zhtml?ticker $=$ FLIR\&script $=410 \&$ layout $=-6 \&$ item $\_$id $=273820$.

FLIR (2003). Detecting SARS with infrared cameras. Retrieved May 2 , 2003 from http://www.flirthermography.com/sars_infrared_info/ default.asp. 
FuCHS, J. (2002). Thermography used in diagnosis of horses' locomotor injuries [Flir publication]. Retrieved November 20, 2002 from http://www.infraredtraining.com.

Gruner, K. (2002). Principles of non-contact temperature measurement [Raytek publication]. Retrieved November 20, 2002 from http://www.raytek.com.

Hermans-Killam, L. (2002a). Infrared zoo. Pasadena, CA: California Institute of Technology, Infrared Processing and Analysis Center. Retrieved November 20, 2002 from http://sirtf.caltech.edu/EPO/Zoo/ zoo.html.

Hermans-Killam, L. (2002b). What is infrared? Pasadena, CA: California Institute of Technology,Infrared Processing and Analysis Center Retrieved November 20, 2002 from http://www.ipac.caltech.edu/ Outreach/Edu/infrared.html.

JANOS (2002). AMTIR-1. Retrieved November 20, 2002 from http://www. janostech.com/techinfo/amtir.html.

Kastberger, G., \& Biswas, S. (1998). Mechanisms in the cascadic alarming response of a giant honeybee colony. Zoology, 101, 48.

Kastberger, G., \& Sharma, D. K. (2000). The predator-prey interaction between blue-bearded bee eaters (Nyctyornis athertoni) and giant honeybees (Apis dorsata). Apidologie, 31, 727-736.

Kast berger, G., Winder, O., Biswas, S., \& Raspotnig, G. (1998). Evidence of Nasonov scenting in colony defence of the giant honeybee Apis dorsata. Ethology, 104, 27-37.

Kastberger, G., Winder, O., \& Steindl, K. (2001). Defence strategies in the giant honeybee Apis dorsata [Scientific documentary film, 23 min. produced by epo-film Wien-Graz]. Proceedings of the Deutsche Zoologische Gesellschaft, 94, 7 .

KLOFT, W., \& SCHNEIDER, P. (1969). Gruppenverteidigungsverhalten bei wildlebenden Bienen (Apis cerana Fabr) in Afghanistan. Naturwissenschaften, 56, 219.

KODAK (2002). Infrared photography-Technical applications. Retrieved August 26, 2003 from http://www.kodak.com/global/en/ service/scienceFair/infraredTechnical.shtml.

Koeniger, N., \& FuchS, S. (1975). Zur Kolonieverteidigung der asiatischen Honigbienen. Zeitschrift für Tierpsychologie, 37, 99-106.

Lindauer, M. (1956). Über die Verständigung bei Indischen Bienen. Zeitschrift für Vergleichende Physiologie, 38, 521-557.

MadDing, R. P. (1982). Science behind thermography: Thermal infrared sensing for diagnostics and control. In G. E. Courville (Ed.), Thermosense V (Proceedings of SPIE, Vol. 371, pp. 2-9). Bellingham, WA: SPIE Press.

MADDING, R. P. (1989). Infrared thermography. In E. C. Guyer (Ed.), Handbook of applied thermal design: Pt. 12. Thermal sensors (pp. 1257 to 12-70). New York: McGraw-Hill.

MADDING, R. P. (2002). Emissivity measurement and temperature correction accuracy considerations. Retrieved November 20, 2002 from http://www.flir.com.

Morse, R. A., \& Laigo, F. M. (1969). Apis dorsata in the Philippines. Laguna, The Philippines: Philippines Association of Entomologists.
Night Vision Goggles Dot Com (2002). About us. Dewitt, LA: Author Available from http://www.night-vision-goggles.com/about_us.html. Ono, M., Igarashi, T., Ohno, E., \& SASAKI, M. (1995). Unusual thermal defence by a honeybee against mass attack by hornets. Nature, 377, 334-336.

OrLove, G. L. (2002). A primer on infrared thermography. Pasadena, CA: California Institute of Technology, Infrared Processing and Analysis Center. Retrieved November 20, 2002 from http://www.ipac. caltech.edu/Outreach/Edu/infrared.html.

RAYTEK (2002). Noncontact infrared temperature measurement. Retrieved November 20, 2002 from http://www.raytek.com

RoEPKe, W. (1930). Beobachtungen an indischen Honigbienen insbesondere an Apis dorsata. Mededelingen van de Landbouwhoogeschoo Wageningen, 34, 1-28.

Seeley, T. D., Seeley, R. H., \& Akratanakul, P. (1982). Colony defence strategies of the honey bees in Thailand. Ecological Monographs, 52, 43-63.

SPI (2002). Horses infrared veterinary medicine equine treatment. Retrieved November 20, 2002 from http://infra-red.hypermart.net/ equine_infrared_veterinary_imagi.htm.

Stabentheiner, A., Kovac, H. \& Hagmüller, K. (1995). Thermal behaviour of round and wagtail dancing honeybees. Journal of Comparative Physiology B, 165, 433-444.

Stabentheiner, A., Kovac, H., \& Schmaranzer, S. (2002). Honeybee nestmate recognition: The thermal behaviour of guards and their examinees. Journal of Experimental Biology, 205, 2637-2642.

Stabentheiner, A., \& Schmaranzer, S. (1987). Thermographic determination of body temperatures in honeybees and hornets: Calibration and applications. Thermology, 2, 563-572.

STAHL, M. (1980). Grundlagen Infrarotteknik. Heidelberg: Hütthig Verlag.

Steketee, J. (1973). Spectral emissivity of skin and pericardium. Physiological \& Medical Biology, 18, 686-694.

Thiesbrummel, J. (2002). IR thermography with zoo animals: First experiences in the use of pregnant and inflammation diagnostics. Retrieved November 20, 2002 from http://www.infraredtraining.com.

Tivey, D., \& BANHAZI, T. (2002). The potential to assess environmental conditions within pig production systems. University of Adelaide, Roseworthy Campus, Livestock Systems Alliance.

Trinkel, M., \& KASt Berger, G. (2003). Interactions between spotted hyenas and lions in the Etosha National Park, Namibia. Manuscript submitted for publication.

Watmough, D. J., \& Oliver, R. (1968). Emissivity of human skin in vivo between $2.0 \mu$ and $5.4 \mu$ measured at normal incidence. $\mathrm{Na}$ ture, 218, 885-886.

Wolfe, W. L., \& Zissis, G. J. (EDs.) (1993). The infrared handbook. Washington, DC: Office of Naval Research.

(Manuscript received November 5, 2002; revision accepted for publication March 16, 2003.) 